\title{
Algo más sobre José María Luis Mora
}

Laura Solares Robles Laura Suárez de la Torre

Seis cartas inéditas intercambiadas entre el doctor Mora, ministro plenipotenciario y Mariano Otero, ministro de Relaciones Exteriores.

\begin{abstract}
... a tanta distancia y despues de tan larga ausencia no me es posible juzgar los hombres ni apreciar las cosas en su justo valor.'
\end{abstract}

J. M. Luis Mora

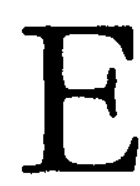

sta queja y justificación que Mora hace a Mariano Otero en la carta del 1 de febrero de 1849, escrita en Londres, responde a circunstancias y momentos decisivos de la vida de dos hombres que nacen entre dos mundos, como señala Reyes Heroles,el agonizante colonial y el moderno que pugna por nacer, así "el hombre que vive entre

1 Carta de Josế Maria Luis Mora a Mariano Otero, Londres, 1 de febrero de 1849, Biblioteca Nacional de Madrid, Ms. 20253, p. 788.

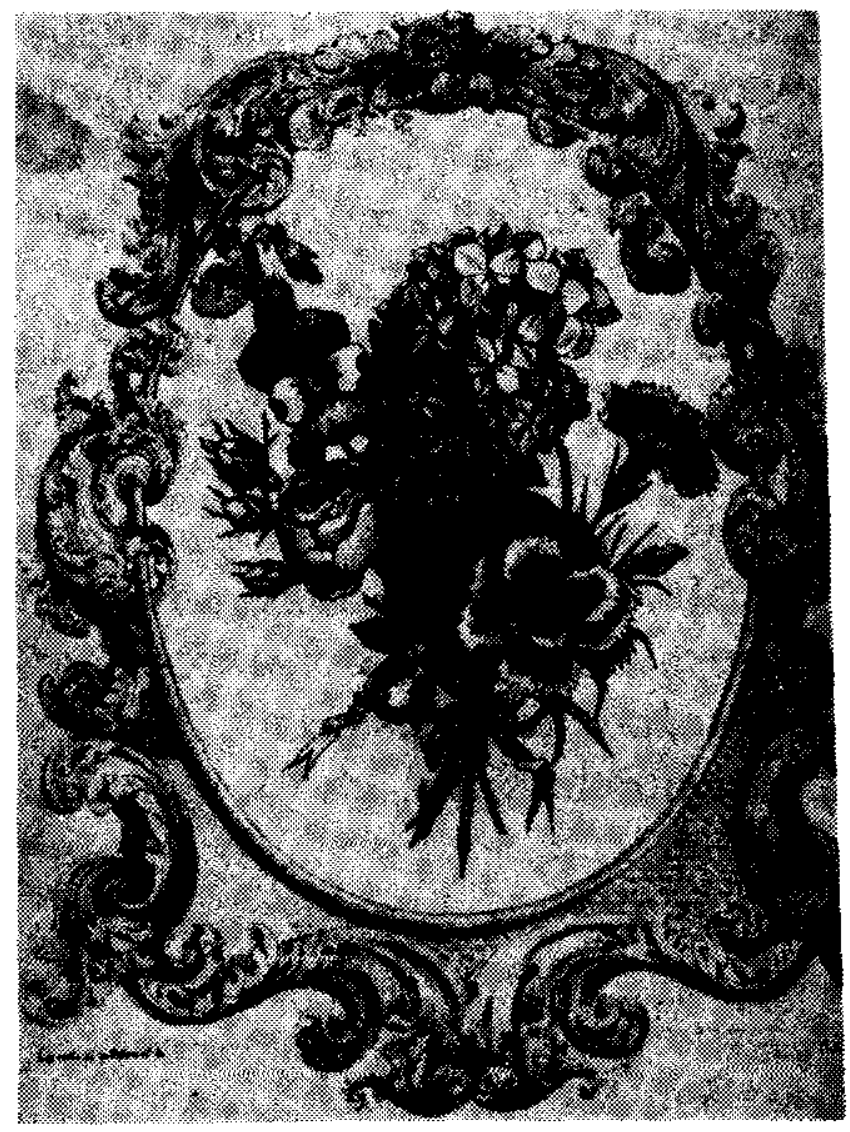


dos mundos llega demasiado tarde o demasiado temprano". ${ }^{2}$

El rescate de una pequeñísima parte del material epistolar de Mora y Otero sirve de pauta y pretexto para escribir estas páginas. Las cartas, testimonio vivo de un momento, responden a situaciones específicas; en ellas se vierte de una manera más personal el sentir de los hombres ya que no tienen la solemnidad de un escrito que se hace con la finalidad de imprimirse o la formalidad de un texto sobre diversos temas como política, historia o literatura; esas cartas, en pocos renglones, ofrecen un sinnúmero de temas y opiniones muy personales que no serían por lo general del conocimiento del estudioso del siglo XIX por su carácter privado y por encontrarse, una gran parte de ellas, en archivos o en bibliotecas del extranjero.

La tarea de compilar las Obras completas de José María Luis Mora implicó la búsqueda de material no sólo en acervos nacionales, tal fue el caso de la Colección Latinoamericana de la Biblioteca Nettie Lee Benson en Austin, Texas, de donde se logró reunir un material novedoso que apareció publicado en ocho volúmenes.

E1 material epistolar de carácter diplomático corresponde a los volúmenes 7 y 8 sobre asuntos nacionales y personales. Las cartas, algunas de las cuales nunca habían sido publicadas, mostraron una nueva faceta del Mora sacerdote, periodista, político e historiador presentando al hombre que amó y tuvo una

\footnotetext{
2 Jesús Reyes Heroles, "Estudio preliminar", en Mariano Otero, Obras, Editorial Porrúa, México, 1967, t. I, p. 10.
}

descendencia de la cual hoy se encuentra perdido su rastro en el viejo continente y que quizá ignora el valor del político mexicano.

Escribir de las personas y de los acontecimientos fue una práctica usual durante milenios cuando los medios para comunicar deseos, noticias o consejos, se reducía a lo que pudiera decirse en simples cartas; documentos que en el quehacer histórico y la modernidad del siglo $\mathrm{XX}$ adquieren una dimensión por demás importante al rescatar todo ese sentir y pensar de los personajes que formaron la historia de nuestro país durante los años aciagos de su conformación como Estado.

Las Obras completas resultan siempre susceptibles de ser enriquecidas con materiales que quedaron fuera en el momento de concebirlas, y que un buen día aparecen para formar parte de lo que parecía completo. Tal es el caso de tres cartas del doctor Mora escritas en Londres en julio 28, agosto 31 de 1848 y febrero 1 de 1849, localizadas en el Archivo de la Biblioteca de Madrid y que gentilmente han sido donadas al Instituto de Investigaciones Dr. José Ma. Luis Mora por el doctor Antonio Martínez Báez.

Este rico material, no publicado hasta el momento, respondió a la necesidad que dos hombres tuvieron de ponerse en contacto al desempeñar cargos públicos en momentos difíciles para la existencia nacional. Nos referimos al desempeño de José Ma. Luis Mora como ministro plenipotenciario de México del 28 de diciembre de 1846 hasta su muerte y al de Mariano Otero en el Ministerio de Relaciones Interiores y Exteriores del 4 de junio al 14 de noviembre de 1848 con el gobierno de José Joaquín de Herrera. 
La correspondencia entre ambos fue prolífica pues abarca un periodo entre 1848 y 1850 , inclusive cuando ya Otero no figura en el ministerio; fue tal el entendimiento que lograron que su correspondencia continúa y sólo se interumpe con la muerte; ambos dejan de existir casi al unisono, Mora fallece en el viejo continente en julio de 1850 , Otero en el nuevo continente un mes antes.

La mayor parte de la correspondencia ya ha sido publicada, ${ }^{3}$ es por ello que en el presente artículo sólo se incluyen las tres cartas de Mora mencionadas. Ellas carecerían de sentido o parecerían aisladas si no se presentaran junto a las de Otero, lo cual nos ofrece un nuevo enfoque de los personajes en su tiempo y circunstancias particulares.

La admiración y reconocimiento que Otero le profesó a Mora se deriva en gran parte de los escritos y actuación pública de Mora en los primeros años de vida del México independiente; si bien sus ideales los acercaban no asi sus tiempos pues Mora en 1833 ya desarrollaba una importante tarea política mientras Otero apenas contaba con 16 años.

La diferencia de tiempos parecería hacer imposible una relación entre ambos, más aún cuando sabemos que Otero, según dice Moisés González Navarro, culpaba a la administración de 33, en la cual Mora jugó un papel decisivo, de las reformas que precipitaron muchos males en la república. ${ }^{4}$ No obs-

3 José María Luis Mora, Obras completas, SEP, Instituto de Investigaciones Jose María Luis Mora, 1988, t. 7 y 8, y Mariano Otero, op. cit., t. II.

1 Moisés González Navarro, "Actualidad de Mariano Otero", en Historia Mexicana, vol. II, núm. 2, octubre-diciembre 1952, p. 288. tante, Mariano Otero consideraría a Mora como el político experimentado, el hombre con visión, capacitado para aconsejarlo en el difícil desempeño del Ministerio de Relaciones; a él acudiría confiado en su buen criterio.

Cabe señalar que a ambos los unió su amor por México y la necesidad de conjugar esfuerzos para resolver los problemas que se presentaron a mediados del pasado siglo y que a pesar de las tareas emprendidas por un sinnúmero de personajes no serían resueltos sino mucho tiempo después; faltaría mucho camino por recorrer para ver el México que sólo en parte fue lo que ellos desearon.

La temática abordada en esta correspondencia se refiere principalmente a las consecuencias de la guerra del 47 , al pago de la deuda, las intrigas e intereses de los extranjeros, la inestabilidad política, las ambiciones del ejército, la desorganización hacendaria y la amenaza de una dictadura. Plantean posibles soluciones a los problemas, hacen juicios críticos sobre situaciones y personajes, retratan el carácter del mexicano y prevén sucesos que serán producto de la no solución de los problemas que presencian.

Políticos reflexivos, nacionalistas apasionados, hombres públicos activos, recelosos de la presencia norteamericana, partidarios de la colonización, del mejoramiento de los sistemas penitenciarios, contrarios a los proyectos monárquicos, simpatizantes del federalismo, servidores de su patria y fieles a sus principios quisieron encontrar en el ejercicio de la política el progreso de la sociedad y la unidad nacional.

La obra de Mora nos legó un rico material escrito que abarca artículos perio- 
dísticos, correspondencia diplomática, asuntos legales, memorias, historia; Otero, más conocido como jurista que como político, no fue tan prolífico en sus escritos como Mora; justo es mencionar que las cartas nos permiten conocer no sólo al político, al historiador o al jurista sino al hombre de carne y hueso que sufre y se alegra, se decepciona y esperanza y que ama profundamente; situaciones que no aparecen reflejadas en escritos de otra índole, de ahí la importancia de valorar en su justa dimensión el material epistolar de ambos personajes ya publicado, y que hoy se acrecienta con las cartas que a continuación se transcriben.

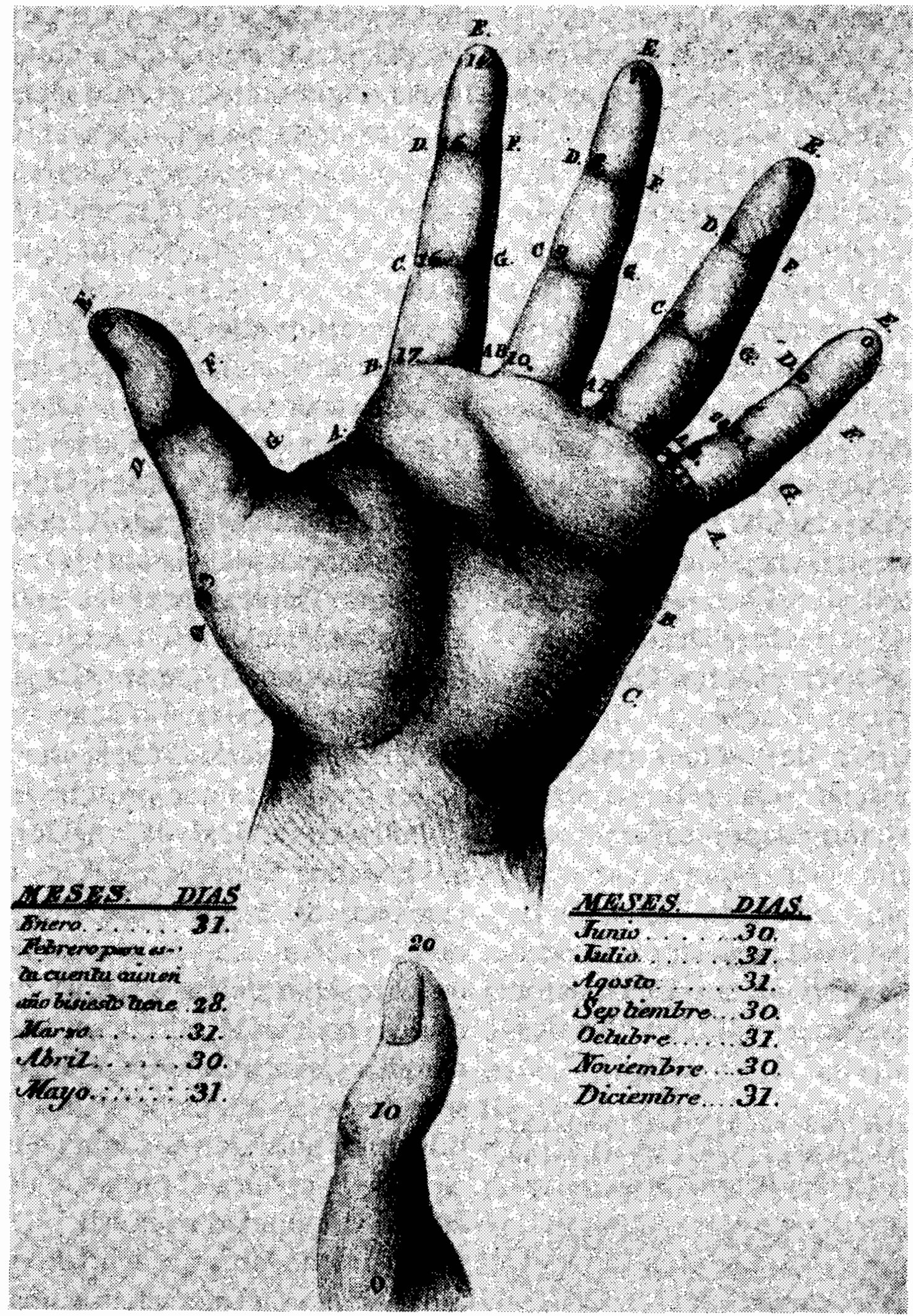


México, junio 13 de $1848^{*}$

Muy señor mío y de mi más distinguida consideración:

Al encargarme del Ministerio de Relaciones que el E.S. presidente quiso confiar a mi buen celo, considero como un deber en extremo grato el de ofrecerle mis servicios. Sin embargo de que no he tenido el honor de conocerle personalmente, a ningún mexicano es extraño el nombre de una persona tan ilustre por sus talentos y servicios y usted ha debido contarme entre el número de los que admiran aquéllos y reconocen éstos.

Yo estimo como una circunstancia propicia para la república el que en una época tan difícil haya estado confiada a usted esa legación, y como creo que los negocios interiores de este nuestro desgraciado país le ocuparán mucho, le suplico que, por bien de él, tenga la bondad de dirigirme sus consejos. Íntimamente convencido de que no tengo las cualidades necesarias para este puesto sólo lo he aceptado confiando en usted que me auxiliarán cuantos quieren de veras salvar nuestra expuesta nacionalidad.

Ayer a las nueve acabó de salir el ejército norteamericano de la capital de la república en medio del orden más completo. De en medio del pueblo reunido no salió una sola voz que turbara el orden y la ciudad presentó el espectáculo de la más completa tranquilidad sin otra fuerza que la de la guardia nacional. El ministro americano dijo que estaba muy agradablemente sorprendido de la admirable conducta del pueblo de México.

Anoche, sin preparativo alguno, entró el E.S. presidente en el palacio nacional.

Por desgracia, los extraños restos de ese ejército que tan mal recibió al enemigo extranjero, amenazaron el orden público: 190 hombres del 14 de Infantería se pronunciaron en San Juan de los Lagos por el ridículo plan del [...] El general Paredes es el infatigable director de estas revueltas: el gobierno está decidido a obrar con la mayor energía. Dios quiera que logre salvar la república.

Ya que se me presenta esta ocasión de ofrecerme a la disposición de usted le reitero con la mayor sinceridad que debe contarme entre el número de sus más apasionados admiradores y que tendré el mayor gusto si se digna enviarme sus órdenes como a su más atento seguro servidor que [...].

LMLB Mariano Otero

-En Mariano Otero, Obras, recopilación, selección, comentarios y estudio preliminar de Jesús Reyes Heroles, Editorial Porrúa, México, 1967, t. II, pp. 755-756. 
Londres, julio 28 de $1848^{*}$

\section{E. señor don Mariano Otero}

Muy estimado señor y amigo de mi más distinguida consideración:

No de vista ni de trato, pero sí de nombre tengo el honor de haber conocido a usted, y hasta a mí que he vivido aislado por tantos años, ha llegado la sobresaliente reputación que ha sabido formarse, que lo ha puesto en estado de hacer servicios importantes a nuestra desgraciada patria.

La muy acertada elección del general Herrera ha llamado a usted a un puesto que le ofrece la ocasión de poner en acción los recursos con que cuenta para lograr un resultado de honor y gloria en la empresa a todas luces ardua y difícil de la reconstitución de nuestro país. Los antecedentes de un hombre de Estado de las calidades de usted hacen asegurar que las esperanzas concebidas no quedarán frustradas, y que México entrará por fin en el sendero de las leyes de que lo han desviado las incesantes rebeliones hasta llevarlo al borde del precipicio. Amarga y muy costosa ha sido la lección recibida y si no sabemos aprovecharla es necesario perder toda esperanza. Los militares que, como usted dice muy bien y como todo México ha visto, han defendido tan mal al país, serán a mi juicio la principal dificultad del gobierno, pues es de temerse que si anteriormente se sublevaban por diferentes pretextos ahora lo harán hasta sin ellos; y yo no alcanzo otro medio de reducirlos y reformarlos, que el establecimiento general de la Guardia Nacional, y la nueva reconstitución del ejército bajo una disciplina muy severa con exclusión de la antigua oficialidad.

Las demás dificultades dejan tiempo para estudiarlas y venir al cabo de ellas; pero ésta tiene un carácter de urgencia, que no da lugar a nada y que todo lo pone en cuestión, sin exceptuar la nacionalidad misma.

Las expresiones lisonjeras con que usted me honra en su carta me son sumamente satisfactorias; ellas son más bien expresiones de la bondad de usted que la de mi mérito personal. Por lo demás usted no se equivoca en el deseo que me anima de servir a mi patria hasta donde alcancen mis fuerzas, por cierto bien escasas. Hasta aquí he hecho lo que me ha sido posible, y si el resultado no ha correspondido en todo o en parte a los deseos del gobierno, no ha sido por cierto debido a la falta de acción o de voluntad

- En Biblioteca Nacional de Madrid, Ms. 20253, p. 505. 
de mi parte. Mientras contaré con la amistad y comunicaciones de usted, que le suplico me acuerde y continúe y con la confianza del gobierno, proseguiré obrando de la misma manera, y cuando el caso lo pidiere no dejaré de hacerle las indicaciones a que me autoriza su carta.

Hoy giro contra ese ministerio la cantidad de 6003 pesos a que monta el presupuesto de esta legación por el segundo tercio de este año, que suplico a usted muy de veras tenga la bondad de pagar, pues siendo yo hombre sin fortuna ni crédito mercantil, y siendo también la vida en esta ciudad infinitamente cara, no me es posible existir en ella sino por la puntualidad y exactitud en el pago de los sueldos.

Don José de Lizardi es la única persona que por más de un año ha trabajado y sin sueldo en la secretaría de la legación; los señores Peña y Rosa en razón de los motivos de queja que el gobierno ha tenido con la causa de este joven, no consintieron en que siguiera trabajando y yo me abstuve de ocuparlo. Hoy la secretaría tiene la dotación competente; pero habiendo servido bien y por largo tiempo, le he de estimar a usted se sirva continuarlo como agregado a la legación puramente ad bonorem, bien seguro de que no será ocupado por mí en sus labores. En cuanto al general Mendoza, hará un excelente secretario, es la honradez y la laboriosidad personificadas, y muy inteligente y expedito para los trabajos de oficina.

Para ser la primera de nuestra correspondencia ésta es una carta bien larga, pero la bondad que usted ha tenido en escribirme el primero me hace reconocer que ni mis cartas ni las indicaciones que contengan serán recibidas con desagrado. Por todo doy a usted las gracias, y tengo el honor de ofrecerle mi estéril amistad, y las expresiones sinceras de mi afecto y estimación con que soy y me reconozco su muy obediente servidor.

QBSM

José María Luis Mora

México, 12 de agosto de $1848^{*}$

Muy señor mío y de mi más distinguida consideración:

Nuestro común amigo Luis de la Rosa, tuvo la bondad de enseñarme la grata de usted de 30 de junio último. Lo que usted anunciaba en ella se ha realizado completamente. Escandón está empeñadísimo en que los

-En Mariano Otero, op. cit., t. II, pp. 757-758. 
millones de la indemnización se destinen a la deuda exterior verificando una operación por la cual se amortice considerable cantidad de bonos y se haga una nueva conversión reduciendo el rédito a $3 \%$, operación en que tiene grande interés el cónsul inglés y los demás agentes tanto nacionales como extranjeros del último contrato.

Sin embargo puede usted estar seguro de que, al menos mientras yo esté en el ministerio, no habrá de hacerse tal operación: la última ha sido gravosa para México y para los acreedores, sin haber dejado utilidad más que al mismo Escandón y a algunos funcionarios públicos, cuyos votos y órdenes se compraron descaradamente. El empeño que se tuvo de arreglar en el tratado de paz la inversión de esa suma en favor de aquel crédito, es una de las cosas que le suscitaron más enemigos y ahora es seguro que si se está entre nosotros el hábito de las revoluciones, probablemente se organizará alguna en favor de la dictadura del general Santa Anna.

Usted dispense que lo haya distraído con esta larga carta y mande lo que guste a su más adicto servidor que atento.

LMLB

Mariano Otero

Londres, agosto 31 de $1848^{*}$

E. señor don Mariano Otero

Muy estimado amigo y señor:

Ha sido imposible tener con lord Palmerston una conferencia formal de manera que pueda darse cuenta con ella al gobierno. Los asuntos de Italia lo tienen de tal manera ocupado que casi todo el día se lo pasa con los asuntos de aquella península, y con los ministros francés, austriaco y de la confederación germánica. Dentro de dos o tres días entraré en materia con él, y por Estados Unidos recibirá usted lo que hubiere de importante, en los puntos sobre que nuestra conferencia debe versar.

Los especuladores o agiotistas sobre fondos mexicanos se han irritado mucho contra mí y contra el gobierno, por la resistencia que han encontrado en acordarles el fondo de la indemnización. Su proyecto era hacer levantar 
momentáneamente el valor de los fondos mexicanos para poder vender con ventaja los que han comprado a bajísimo precio, y una vez obtenido este lucro considerable, poco les importaba el que más tarde México dejase de pagar y los fondos bajasen como bajarían enormemente.

Yo creo que el gobierno debe mantenerse firme e invariable en las resoluciones adoptadas, sin dejarse intimidar por amenazas que, puede usted estar seguro, no tendrán efecto mientras se mantengan religiosamente las hipotecas convenidas en bono; pues todos los que no son especuladores reconocen aquí la justicia que

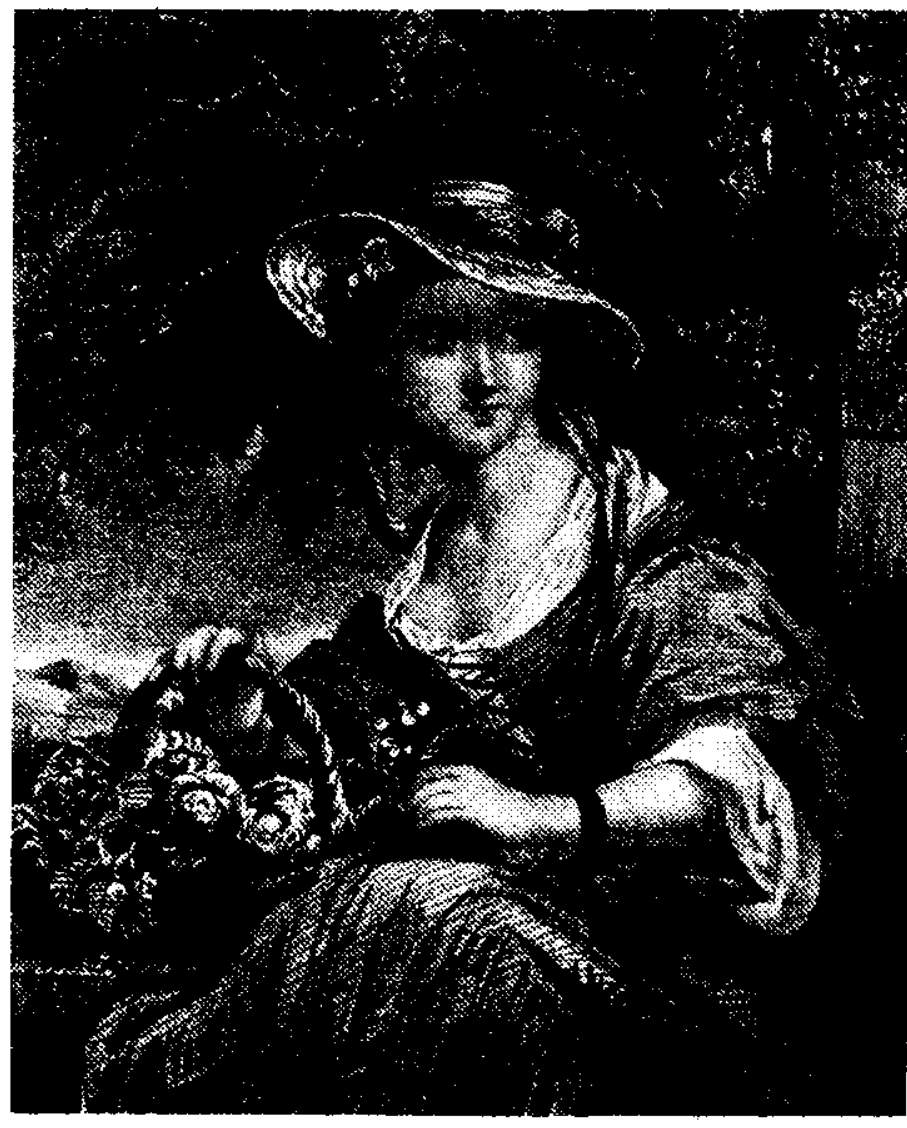
nos asiste para rehusamos a lo demás. Los especuladores [...] no poder con la promesa de aplicar el fondo de indemnización aunque ella se hiciera sin resolución de cumplirla; así pues no dejarán de solicitarla aunque sea lejana, porque desde que ella se haga hasta el plazo en que debe tener efecto, los bonos subirán de precio y la ganancia se efectuará.

Hemos sabido por Estados Unidos la derrota de los sublevados, y ayer he visto una carta de México del 25 de julio en que esta noticia se confirma; con este suceso el gobierno, lejos de perder, ha ganado en la insurrección, y espero que éste será el término de tantas revueltas como han asolado al país. Lo que puedo asegurar a usted es que en los círculos de por acá se tienen grandes esperanzas de la administración actual, de las personas que la componen, de las influencias que la inspiran, y del partido que la apoya.

Me parece necesario decir a usted que hasta 1846 ha habido poca fidelidad en los empleados de los ministerios, pues me consta por lo que yo mismo he visto, que asuntos muy reservados han llegado a conocimiento de los interesados, que han obtenido constantemente copias de las comunicaciones de los ministerios a las legaciones, especialmente en materia de hacienda. Por otra parte es de necesidad no dar ocasión a ciertas personas de que puedan jactarse, como lo hacen, de poder lograr cuanto quieran con sumas más o menos considerables, y de esto hay mucho como usted habrá advertido.

No he querido dejar pasar la ocasión de escribir algunas líneas para anunciarle las importunidades que le aguardan, y prevenirle contra ellas. $\mathrm{Si}$ 
lo lograre me daré por satisfecho, y entre tanto tengo el placer de repetirme su muy afecto amigo y obediente servidor.

José María Luis Mora

México, 14 de diciembre de $1848^{*}$

Muy estimado señor y amigo:

Hasta ayer en la tarde recibimos la correspondencia del paquete inglés, que me trajo la muy grata de usted de 31 de octubre que contesto.

Mucho me alienta el que los actos del gobierno mexicano comiencen a recibirse en Europa de una manera favorable y aunque yo esté ya fuera del gobierno, por los disgustos que indiqué a usted, en el Senado y en cuanto yo conserve algún influjo trabajaré con constancia por que la administración no me separe de los únicos principios en que podremos confiar para la salvación de nuestra nacionalidad. Por fortuna el resultado de las elecciones en Estados Unidos ha sido favorable a Taylor y esto nos da la ventaja de contar con que por algún tiempo el gobierno americano no trabajará en complicar nuestra situación y traernos a un nuevo conflicto.

Lo que me desconsuela un poco es conocer que la base de todas las reformas está en el arreglo de la Hacienda y el ejército y en eso avanzamos poco. El señor Piña y Cuevas no me parece capaz de llevar al cabo, quizás ni aun de concebir un arreglo tan complicado, tan difícil, como el que se necesita para introducir el orden en la imposición, la economía y moralidad en la recaudación, la justicia en la repartición de los impuestos para hacer cesar el movimiento del agio y obrar sobre nuestra deuda; una grande operación además en las cámaras, lejos de tener el prestigio necesario para contar con la ayuda del cuerpo legislativo, encuentra una oposición que pronto lo hará dejar la cámara. En materia de fuerza el egoísmo y la indolencia de nuestras costumbres hacen que la guardia nacional exista en poco número y mal organizada; de nuestros soldados nada puede esperarse y a mi juicio debemos renunciar a toda esperanza de un buen ejército si no nos decidimos a traer alguna persona extranjera y buenos jefes y oficiales.

He leído la memoria del señor Murphy sobre la deuda exterior y en efecto ella presenta en toda su deformidad la conducta de la administración

'En Mariano Otero, Obras, op. cit., pp. 767-765. 
del 42 que autorizó las más indignas operaciones; pero no me parece igualmente imparcial y justa respecto de las operaciones de la última conversión, operación imprevisiva que nos comprometió a más de lo que podíamos cumplir y en la que el interés de Mackintosh y de Escandón se sacrificaron al interés de los acreedores y el crédito de la república. [...] la historia secreta de este negociado abunda quizá más que cualquier otra en incidentes de corrupción y de vergüenza.

Por acá estos señores no cesan de trabajar y desde mi salida del ministerio lo hacen ya con mejor éxito pues el actual ministro siempre les ha sido muy favorable. Ahora acaban de conseguir una injusticia. Usted sabe que el Congreso previno al gobierno celebrara un arreglo con los acreedores del tabaco; que al efecto se tuvieron varias conferencias con los señores principales que eran los cosecheros a quienes se les debe el tabaco entregado en dos años, los tenedores de bonos de la antigua empresa y los de la deuda exterior; pues aunque en rigor de justicia estos créditos tienen una graduación ya clasificada se esperaba que cedieran algo de su derecho y tuvieran un convenio armonioso. De pacto los cosecheros y los tenedores de la antigua empresa de bonos habían convenido en recibir cada uno sólo 20000 pesos cada mes y dejar el recibo a los tenedores de bonos de la deuda exterior, con lo que éstos obtenían notables ventajas que, según la conversión, antes de sacar de la venta la parte a ellos asignada debían cubrirse los gastos de administración (cosecheros) y la hipoteca establecida en favor de la antigua empresa. Sin embargo Mackintosh no quiso convenir y el complaciente ministro de Hacienda ha determinado que los productos de la venta se repartan con igualdad entre estos tres acreedores.

Semejante providencia excede las facultades del gobierno que no puede alterar los derechos de los acreedores entre sí, que es atentatoria a los cosecheros, que conforme a la sentencia dada en favor de los empresarios, deben cubrirse primero que éstos y que tienen igual preferencia respecto de la deuda exterior por los caminos mismos de la conversión y atentatoria también contra los antiguos empresarios que por su sentencia tienen derecho a ser cubiertos de preferencia a la deuda exterior. El resultado es que unos y otros ocurrirán al Congreso, y a la Corte de Justicia y obtendrán allí que se les aplique la parte que ahora se designa a la deuda; con lo cual probablemente se volverá a poner el grito en el cielo sobre la inestabilidad de nuestros arreglos. El negocio de intento se ha concluido en los días próximos a la salida del paquete, probablemente para que la noticia de esta concesión injusta produzca algún efecto en el mercado; y precisamente con ese mismo fin he hecho yo publicar en $E l$ Siglo $X I X$ de ayer ese párrafo, que acompaño, para que así por el mismo paquete que la noticia de la orden del 


\section{SECUENCIA}
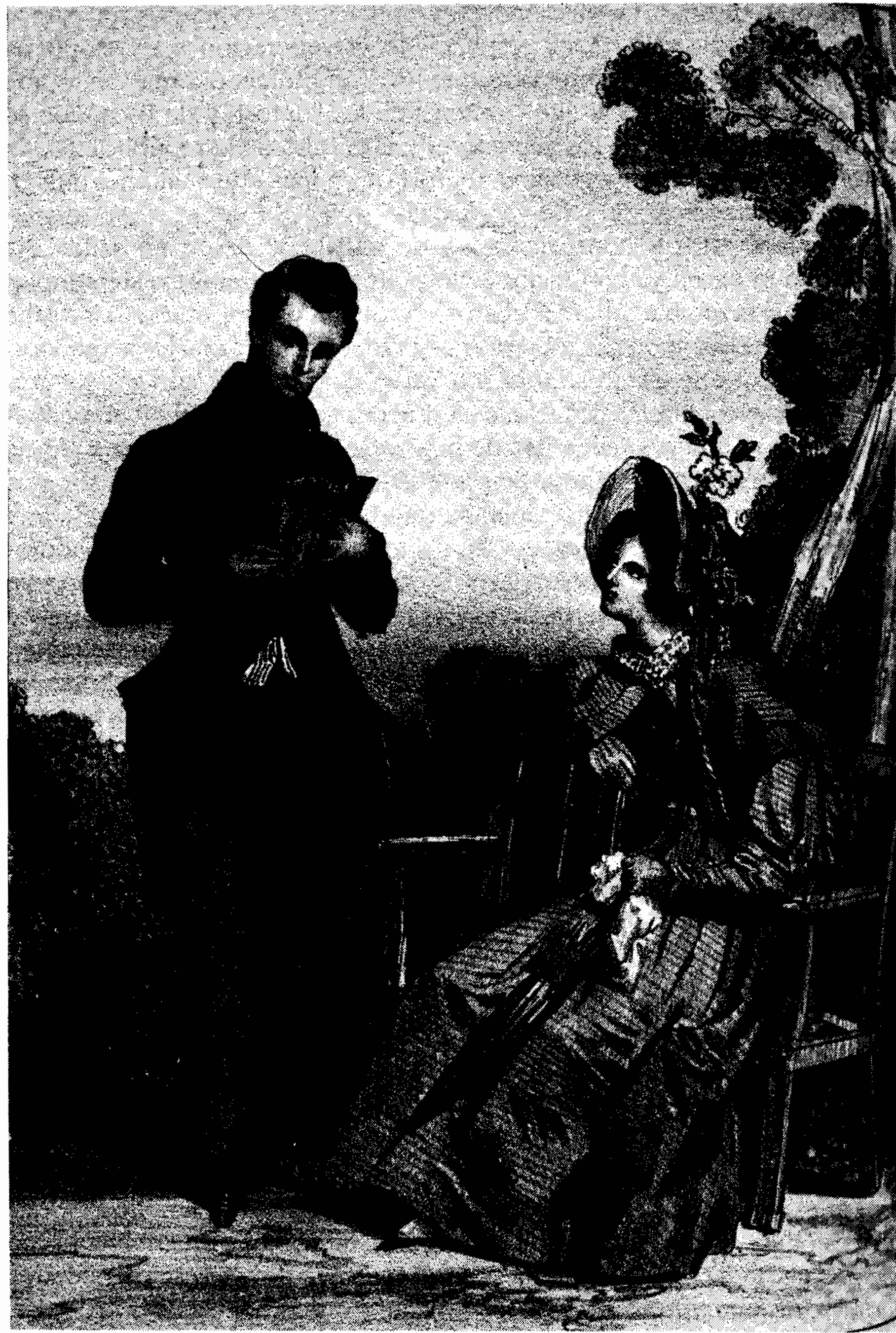
gobierno vaya la de que ella va a ser reclamada por los ofendidos. Creo que usted haría un bien haciendo que se publicara traducida y explicada y al efecto la acompaño.

Lo que usted ha meditado sobre la manera de obtener una buena colonización, me parece tan exacto y tan previsor que yo quisiera que se adoptase como un principio invariable de nuestra política; una nueva imprudencia puede reproducir lo de Texas con consecuencias más deplorables.

Pero ya ésta es muy larga y así concluyo. La estimación y el afecto que por muy justos títulos profeso a usted son invariables así como es constante mi deseo de serle útil y me lisonjeo con la esperanza de que usted continuará contándome entre el número de sus amigos y me favorecerá con sus estimables letras y sus importantísimos consejos. Yo tengo mucho placer en repetirme de usted muy adicto amigo y servidor que atento.

LMLB

Mariano Otero

\section{Londres, febrero 1 de 1849* \\ E. señor don Mariano Otero}

Muy estimado señor y amigo:

Con el mayor sentimiento, he visto su muy apreciable carta que me confirma lo que yo ya sabía desde primero de enero por la vía de Estados Unidos, a saber, su salida del ministerio. Esta ocurrencia no interrumpirá nuestra correspondencia y amistad, que por mi parte seguirán invariablemente las mismas. Yo he sabido apreciar el mérito de usted antes de comunicarlo y sus cartas no han hecho sino afirmar en mí este concepto, las recibía con interés y las contestaba con placer.

Nuestra situación por acá es la misma que en el mes anterior y si el gobierno sigue obrando como hasta aquí, el crédito de México podrá levantarse aunque en un lentísimo grado de progresión. Yo ignoro las relaciones que existen entre el nuevo ministro y los especuladores, así como el partido que éstos proponen sacar de él. Pero si logran desviarlo de la senda emprendida, esto causará incalculables males al país por la ruina del erario, que es el elemento más necesario para reconstituirlo y que es la consecuencia inevitable de semejantes hombres sobre el gobierno. No es un síntoma

'En Biblioteca Nacional de Madrid, Ms. 20253, p. 788. 
la resolución tomada sobre el tabaco que usted me comunica, pues si ella no puede tener efecto por una sentencia adversa de la Corte de Justicia, es una promesa hecha y no cumplida a los tenedores y un motivo de descrédito; hasta ahora los interesados se han abstenido de publicarla aquí, y por este motivo yo he suspendido cumplir con el encargo de usted que desempeñaré con gusto luego que lo hagan, lo mismo que con los que usted tenga a bien encomendarme de nuevo.

Profundamente convencido del estado de desorganización en que se hallan todos los ramos de la administración pública en nuestro país ni me admira ni me sorprende lo poco que en ella se adelanta. Yo jamás he creído en milagros políticos, y nada he esperado sino del tiempo y el trabajo; así pues, mis deseos han sido modestísimos y reducidos a que la obra empiece y se continúe aunque en una escala insensible de progresión; pero si se hace lo que antes, es decir, nada, si se deja arruinar lo poco que ha sobrevivido a la catástrofe universal, y si el ministerio en lugar de gobernar sólo piensa en vegetar, entonces todo será perdido y esto es lo que yo temo mucho que suceda.

Ignoro y desearía saber cuál es el verdadero motivo de la retirada de usted, pues esto sólo podrá ser la clave segura y el medio de conocer la marcha que va a seguirse, pues a tanta distancia y después de tan larga ausencia no me es posible juzgar los hombres ni apreciar las cosas en su justo valor.

Por acá las cosas siguen en la inestabilidad que les ha impreso la revolución de febrero. Lo que parece repararse en un mes se pone en cuestión y aun es demolido en el otro. La Italia se halla en la más exagerada anarquía; la Alemania en reacción que hasta ahora no va muy lejos; la unidad de esta raza en un gobierno es una empresa imposible hoy más que nunca. Francia ha empezado su ensayo republicano con elementos monárquicos que tienden a donde es natural. En fin nada hay que pueda llamarse seguro ni que presente los caracteres de fijeza y estabilidad sino en Inglaterra y en Francia.

Esta carta no va por la vía del ministerio, sino directamente a usted, y le suplico que para lo sucesivo las suyas vengan por la vía ordinaria poniendo en el sobre, además de la dirección común, lo siguiente: 7 Gloucester Road Regent's Park.

De nuevo ofrezco a usted mi amistad y servicios a pesar de lo poquísimo que ellos valen y el ningún empleo que de ellos pueda sacarse, y con la sinceiidad de siempre tengo el placer de repetirme su muy afecto amigo y obediente servidor. 